\title{
REGULARIZACIÓN DE LA PROPIEDAD EN LA SELVA LACANDONA: CUENTO DE NUNCA ACABAR GABRIEL ASCENCIO FRANCO TUXTLA GUTIÉRREZ, UNICACH, 2008
}

Tim Trench UNIVERSIDAD AUTÓNOMA CHAPINGO, sede Chiapas

El tema de la regularización de la tierra en la Selva Lacandona, Chiapas, ha atraído el intenso interés de diversos actores en años recientes. Organizaciones no gubernamentales, locales y nacionales, periodistas y hasta organizaciones más allá de las fronteras de México, han seguido el tema de cerca desde diversos puntos de vista a lo largo de la última década. Seguramente, pocos programas de ordenamiento agrario han recibido tanta atención; aun sin ser un tema normalmente asociado con las portadas de periódicos nacionales o las páginas web de grupos simpatizantes con el Ejército Zapatista de Liberación Nacional, EZLN, en Berlín, Roma o Barcelona. Este interés se debió a la mezcla de ingredientes particulares del caso de la Selva Lacandona: un movimiento armado, una reserva de la biosfera altamente estratégica y una historia de acciones agrarias incompetentes, contradictorias y poco justas. Sin embargo, a pesar de todo el interés mostrado, hasta ahora se había echado en falta un estudio más riguroso e imparcial del proceso. Con la publicación de este libro, Gabriel Ascencio logra llenar el considerado hueco existente en la literatura académica.

Aunque fue imprescindible el seguimiento de la sociedad civil y la prensa a lo largo de la investigación descrita en el libro del Dr. Ascencio, también es importante señalar que dicho seguimiento fue acompañado por un pobre manejo de la información por parte de varios comentaristas y algunos periodistas. ${ }^{1}$ Muchas críticas al proceso en su conjunto quedaban muy vanas al señalar que la Selva Lacandona era una región muy 
estratégica y que el programa agrario representaba una táctica de despojo hacia los pueblos indígenas para vender a empresas trasnacionales el petróleo, agua y biodiversidad, presentes en la región. La preocupación es legítima, pero la complejidad de la situación, junto con la diversidad de los actores — sobre todo indígenas—, la tensión entre el derecho agrario y el imperativo de conservar los remanentes de selva alta perennifolia en la región, desafían ciertos análisis simplistas.

Es en este contexto, polémico y algo confuso, que Gabriel Ascencio nos ofrece Regularización de la propiedad en la Selva Lacandona: Cuento de nunca acabar: libro conciso en el mejor sentido de la palabra, menos de 200 páginas, muy bien escrito y de gran relevancia actual.

Para quienes tenemos un particular interés en esta región, la investigación que llevó a cabo el autor nos sirve a la hora de despejar muchas dudas sobre el proceso agrario de los últimos años; dudas sobre la relación entre lo agrario y lo ambiental, la identidad de los protagonistas, el dinero invertido, el carácter de las negociaciones, la superficie afectada, las implicaciones para el manejo sustentable de la región, los errores cometidos, las lecciones por aprender y la trascendencia del programa a medio y largo plazo.

La publicación consta de cuatro capítulos: 1. El contexto regional, 2. Problema agrario y tratamiento del conflicto, 3. Proceso de negociación y resultados, y 4. La trascendencia del programa. Se enfoca principalmente en el trabajo del «Programa de Atención Integral a la Comunidad Zona Lacandona y la Reserva de la Biosfera de Montes Azules», establecido en junio de 2003, que concluyó operaciones al terminar el último sexenio a finales de 2006. También el texto nos proporciona los antecedentes de este Programa: la mesa agraria-ambiental que se dio durante el gobierno de Roberto Albores Guillén, 1999-2000, y la mesa ambiental celebrada en los primeros dos años de 
la administración del gobernador siguiente, Pablo Salazar Mendiguchía. Estos espacios iniciales fueron liderados por el gobierno del estado y SEMARNAT, respectivamente, presentando alcances muy limitados, así como la constante amenaza de desalojos violentos y algunas reubicaciones mal pensadas y ejecutadas.

No obstante, la instalación del Programa en junio de 2003 representó un momento significativo. Por fin, parece que el espíritu de concertación ganó al del autoritarismo debido a una voluntad política desde arriba, las sinergias interinstitucionales necesarias para lograr los objetivos estaban en un principio concertadas, de igual manera había una operadora con suficiente destreza política - y paciencia— para negociar soluciones pacíficamente desde la propias comunidades. Otro factor clave fue el financiero, ya que el Programa disponía de suficientes fondos para poder «resolver» el problema, además se inscribió en la metodología establecida por la Secretaría de la Reforma Agraria, SRA, para enfrentar los focos rojos agrarios en todo el ámbito nacional, donde se enfatizaba la sensibilización, la concertación y conciliación, y la firma progresiva de acuerdos.

En la opinión del autor:

Se trata de una intervención gubernamental atinada, cuyos agentes dispusieron del instrumento de trabajo adecuado y las condiciones burocrático-administrativas pertinentes, además del conocimiento de la problemática ganado en años de contacto y participación en ella desde la trinchera gubernamental, desde el ámbito del sector agrario federal y de la SRA en particular (p. $70)$.

Es importante enfatizar que el nuevo programa fue coordinado por la Secretaría de la Reforma Agraria; esto porque el problema de la tenencia de la tierra en la selva no es una cuestión ambiental, aunque tenga impactos ambientales, sino agraria; no es ilegal 
habitar dentro de la reserva siempre y cuando se respete la zonificación y el programa de manejo, pero un predio no puede tener dos dueños. Para bien o para mal, $72 \%$ de la Reserva de la Biosfera de Montes Azules, RBMA, corresponde a la Comunidad Lacandona. Sin embargo, desde su decreto en 1972 han existido áreas dentro de la Comunidad Lacandona con dos «dueños», Uno de jure — la Comunidad Lacandona— - y otro de facto - los diversos propietarios-ejidatarios_- causando un sinfín de conflictos territoriales que se han intensificado con la dinámica demográfica regional, con la contrarreforma agraria de 1992 y con la vigorosa organización política de múltiples expresiones en el encuadre geográfico de estudio.

Vale la pena compartir algunos rasgos y datos generales del Programa, que se encuentran en el libro, para ir dimensionándolo. En poco más de tres años dicho Programa gastó en total $\$ 580,000,000$ de pesos en 4,135 beneficiarios, de los cuales 1,678 correspondían a comuneros de los Comunidad Zona Lacandona, CZL. Cabe señalar que esta cantidad representa más que la inversión total de PRODESIS $^{2}$ en la región. De las 141,092 hectáreas «regularizadas» hasta octubre 2006, solo 5\% fue recuperado a través de desocupaciones o reubicaciones En cambio, de esta superficie 66\% resultó regularizada a través de la expropiación de tierras de la CZL y la legalización de los poblados existentes. Estos datos contrastan con la versión expuesta en muchas otras fuentes. Ahora es importante reconocer que la Comunidad Lacandona recibió en total $\$ 465,000,000$ de pesos como indemnización por pérdida de territorio; es decir, casi $80 \%$ del dinero disponible para el Programa. Este hecho no recibe tanta reflexión en el libro, cuando resulta ser uno de los resultados más cuestionables del proceso.

El autor considera que muchas de las negociaciones fueron «auténticas», en el sentido de que algunos de sus participantes pudieron incidir en los términos de su 
reubicación o desalojo y en las indemnizaciones que recibieron por perder su territorio. El libro demuestra no solo cómo la Comunidad Lacandona logró aumentar el precio de las tierras expropiadas — de $\$ 4,500$ a $\$ 10,000$ por hectárea—, también cómo algunos de los poblados que acordaron desocupar sus predios dentro de la CZL asimismo lograron conseguir mayores compensaciones. Llama la atención, por ejemplo, el caso de Ojo de Agua El Progreso, en donde los pobladores choles lograron una compensación de $\$ 280,410$ por familia en vez de $\$ 30,000$ que se les ofreció inicialmente. En total, las 73 familias beneficiadas recibieron un monto de $\$ 20,470,000$ por las 2,047 hectáreas que desocuparon, con el que compraron después un terreno en Balancán, Tabasco.

Sin embargo, a pesar de un comienzo auspicioso, el autor nos explica a detalle por qué el proceso se desvirtuó en el último año de su operación, debido a las características prisas sexenales, el cambio de personal clave y la ausencia de procesos de autoevaluación. El libro detalla cuidadosamente cómo el Programa cayó en viejas prácticas clientelares, con resultados bastantes perversos, debido a la premura que tenían diversos actores por «terminar» el proceso antes de diciembre de 2006. Estas relaciones clientelares se manifestaron en el caso de la Comunidad Lacandona — que recibió un trato indiscutiblemente preferencial durante todo el proceso- $-\mathrm{y}$ de igual manera en el caso de otros poblados. Como ejemplo absurdo de esta dinámica, el autor nos cuenta la historia de la reubicación de Nuevo Magdalena, constituido por varios poblados irregulares, en donde SRA atendió la demanda de los futuros beneficiarios otorgando dos balones marca Voit, ocho uniformes de básquet color azul e igual número de pares de tenis, además de pedir que fueran llevados a Tuxtla Gutiérrez para asistir a las fiestas del 15 de septiembre (p. 104).

Aunque las reubicaciones no representaron el eje primordial del Programa —ni en términos del dinero dedicado a ellas ni en el número de beneficiarios- fueron sin 
duda la parte más visible del mismo. Así, el autor nos ofrece una evaluación de esta parte de la estrategia, dedicando veinte páginas a los casos de tres nuevos asentamientos creados por el mismo Programa: Santa Martha, Nuevo Magdalena, Nuevo Montes Azules. Si el primero se constituyó como «modelo», el caso de Nuevo Montes Azules sirvió de lección en el sentido de cómo no se debe llevar a cabo una reubicación, y esperemos que al menos nos dé las pautas para evitar más desastres sociales de estas características en el futuro. En este particular la reiterada falta de coordinación entre las dependencias gubernamentales encargadas del «desarrollo» del nuevo poblado significó que, por un lado, muchos regresaran a su lugar de origen y, por el otro, que la gente se volviera totalmente dependiente de los apoyos gubernamentales.

Con respecto a las fuentes que empleó el autor, queda claro que tenía acceso privilegiado a los documentos no publicados de SRA y de los actores claves del Grupo Operativo de Trabajo, GOT, del Programa en Tuxtla Gutiérrez. Se aprecia que tuvo la oportunidad de acompañar al personal del Programa en varias ocasiones, así pudo observar de cerca los procesos de concertación y negociación en las comunidades y en la capital. También, la posibilidad de hacer trabajo de campo independiente para verificar los hechos en el terreno incrementa el valor de la publicación. Todos estos elementos confieren bastante autoridad a la versión de los acontecimientos que nos comparte el autor.

Sin embargo, caben señalar algunas ausencias en la investigación, aspectos que podrían haber sido incluidos para enriquecer nuestra visión ante el problema planteado. Por ejemplo, las comunidades que se negaron a dialogar con el gobierno no están incluidas en este estudio, y desconocemos sus perspectivas y razones por las que rechazaron la oferta institucional. A veces, al depender tanto de las fuentes oficiales, surge la duda de que en ocasiones el texto podría estar reproduciendo algunos sesgos y 
juicios de valor del personal de SRA en su interpretación del proceso. Todos reconocemos que los informes de avances de las Secretarías a veces no reconocen la complejidad social del campo de acción, enfatizando más los supuestos avances que los obstáculos encontrados con el afán de asegurar el cumplimiento de los objetivos ya establecidos.

En otro sentido, surge la duda de que el libro tal vez reproduzca algunos de estos sesgos o puntos ciegos del Programa en su interpretación de los hechos. Un ejemplo sería la falta de atención a 28\% de RBMA, que queda fuera de CZL y se ubica en la región de Laguna Miramar. Por ejemplo, en el Cuadro 15 del libro (p. 156), solo se identifica un predio irregular que se encuentra en RBMA pero fuera de CZL. De hecho, existen al menos seis poblados irregulares en esta región — cuatro de ellos dentro de la zona núcleo que ahora es zona federal, después de la expropiación de 22,000 ha de terrenos nacionales; y dos fuera de ella-. Aunque se mencionan los nombres de estas comunidades, en el contexto de la expropiación llama la atención que hayan quedado fuera de las prioridades actuales; me refiero a Benito Juárez, Chumcerro La Laguna, Nuevo Villaflores, Ojo de Agua La Pimienta, Nuevo Aguadulce y Nuevo Limar.

Otra ambigüedad que el libro presenta es la malentendida pero importante diferencia entre el polígono original de CZL, plasmado en el decreto de 1972, correspondiente a 614,321 ha, y el plano definitivo establecido con la ejecución del decreto de 1988, que cuenta con una superficie menor de 501,106 ha. Aunque en el libro nos dice que en febrero 2005 el GOT logró establecer que los participantes en las negociaciones iban a tomar estos once polígonos como la base para la negociación (p. 132), en los cuadros y algunos de los mapas del libro se sigue manejando la cifra 614,321 ha y el polígono original. 
Tal vez para no aventurarse o no abrir demasiado el universo de estudio, a veces el autor deja las explicaciones de los hechos en un primer nivel; es decir, explica los procesos con base en las realidades regionales y en ocasiones con las nacionales, pero no arriesga una explicación más allá de ello que señale tendencias internacionales o procesos similares en otras partes del país. Tampoco enfrenta, por ejemplo, la acusación frecuente de que este programa de regularización agraria sirvió a los intereses del capital trasnacional y responde a las exigencias de instituciones internacionales. Quizá un análisis de este tipo sea pedir demasiado, o posiblemente para el autor estas interpretaciones de los hechos no fueron sustantivas para el estudio que presenta.

No obstante de las acertadas críticas al Programa, Gabriel Ascencio muestra una opinión generalmente positiva del proceso que cubre el libro, viéndolo como un «esfuerzo organizativo» orientado a «ganar gobernabilidad, alcanzar la estabilidad requerida como plataforma para el cambio productivo local necesario en el entorno de las exigencias ambientales vigentes y de justicia social urgentes» (p.141). En este sentido, Ascencio Franco reconoce la eficacia del Programa y la capacidad del sector agrario para encontrar soluciones y alcanzar los objetivos planteados, invitando a éste concluir la tarea en la región.

Desafortunadamente, el Programa se cerró en diciembre 2006 sin terminar su trabajo, y todavía hay casos pendientes, sobre todo en la zona núcleo de la Reserva y en dos poblados situados en la cuenca del Río Negro. Sólo ahora estamos viendo las repercusiones sociales de las dos expropiaciones a favor de SEMARNAT — la zona núcleo de la Reserva y el predio Las Estrellas—, además la falta de definición en torno a estos decretos amenaza con descomponer la poca confianza que se había logrado en la región de Las Cañadas. Se añaden los torpes desalojos efectuados en agosto de 2007 en 
Buen Samaritano, Nuevo Salvador Allende y El Innominado, mismos que parecen señalar un regreso a la política autoritaria de sexenios anteriores.

Es importante mantenernos alerta ahora que el gobierno del estado ha tomado de nuevo el control del proceso. Efectivamente, el cuento no se ha acabado.

\section{Notas}

${ }^{1}$ Por ejemplo, algunas confusiones principales que circulaban en periódicos y en materiales de algunas ONG eran - y siguen siendo-: 1. Asociar la Comunidad Zona Lacandona, CZL, únicamente con la etnia lacandona cuando representa menos de $15 \%$ de CZL —ignorando a los comuneros tseltales y choles de Nueva Palestina y Frontera Corozal—; 2. Considerar el decreto de la Reserva de la Biosfera de Montes Azules; RBMA, como expropiatorio — cuando solo regula el uso de suelo-; 3. Exagerar la influencia de la dirección de RBMA en el proceso de regularización y reubicación —el director de la reserva nunca participó en las mesas de negociación.

${ }^{2}$ Proyecto de Desarrollo Social Integrado y Sostenible. Iniciativa bilateral de la Unión Europea y el gobierno del estado de Chiapas con un financiamiento de treinta y un millones de euros.

Fecha de recepción: 19 de mayo de 2008

Fecha de aceptación: 29 de julio de 2008 